University of San Diego

Digital USD

$12-30-2019$

\title{
Old Dogs and New Tricks: Facilitating Implementation of Contemporary Academic Technology with an Aging Teaching Population
}

Jack B. Hamlin PhD

National University, jhamlin@nu.edu

Heather J. Leslie PhD

University of San Diego, hleslie@sandiego.edu

Follow this and additional works at: https://digital.sandiego.edu/ldc-scholarship

\section{Digital USD Citation}

Hamlin, Jack B. PhD and Leslie, Heather J. PhD, "Old Dogs and New Tricks: Facilitating Implementation of Contemporary Academic Technology with an Aging Teaching Population" (2019). Learning Design Center: Staff Scholarship. 3.

https://digital.sandiego.edu/ldc-scholarship/3

This Article is brought to you for free and open access by the Learning Design Center at Digital USD. It has been accepted for inclusion in Learning Design Center: Staff Scholarship by an authorized administrator of Digital USD. For more information, please contact digital@sandiego.edu. 


\title{
Old Dogs and New Tricks: Facilitating Implementation of Contemporary Academic Technology with an Aging Teaching Population
}

\author{
Jack B. Hamlin \\ National University \\ Heather Leslie \\ University of San Diego
}

Using a conversational approach, the authors address two fundamental dynamics of online education; engagement with students using online education technology and preparing "older" educators to use that technology. The authors present a discourse about the training of an older professor by a younger technologically savvy professor through the team-teaching of an online course called Facilitation Fundamentals. The professors redesigned the course with the goal of making it more engaging and authentic for adult learners. The redesign of the course is discussed as well as the teaching strategies used and technological hurdles the professors had to overcome. Finally, the professors reflect on the experience and the impact this approach had on students.

Keywords: Facilitation, Online Learning, Adult Learning, Online Teaching, Team Teaching

\section{PREFACE}

Until the past 25 years, little has changed in the manner with which educators in higher education deliver course content since the $12^{\text {th }}$ Century. A radical change in instructional delivery has occurred with the advent of the internet as a primary medium of communication. With the exponential growth of online learning, many educators struggle with being "left in the dust" due to the rapid changes in technology. The journey from chalkboards and mimeographs through whiteboards and Power Points to complete online delivery has been intimidating and frustrating for many whose lives have been spent in academics; and are now looking at the twilight of their academic life and wondering, "What next?"

In response to this change and the need to train its educators, National University has created a faculty professional development program. The goal is to create a culture of online teaching innovation in which members of the faculty community can experiment with new methods, reflect on their practice, and share their findings. Two academics who met through this program decided to team-teach a course together.

What follows is a look at the particular journey of these two academics toward the implementation of new academic delivery techniques; the facilitative academic and the "seasoned" academic. Specifically, what was the common ground, what were the obstacles, how were they overcome, and finally what was the result of their efforts. The conclusion is a discussion of what they found successful, what needs modifications, and to a much smaller degree, what simply will not work. 
Most always, I tell my students, "Do not write in the first person. It is neither professional, nor academic." But then rules are made to be broken. If not broken, then like a reed in the river we must learn to bend (the rules) or be broken ourselves. Therefore, we have decided to present this article in the first person as a chronicle of our journey to "teach an old dog new tricks."

In conceiving this article, we decided to take a pragmatic approach to a subject which we are certain faces many teachers in an ever-changing educational landscape; the accelerated use of technology in teaching. We will discuss the obstacles that a "vintage" teacher must overcome to stay on pace with what appears to be the often-insurmountable task of effectively using technological tools to facilitate the classroom experience in a virtual setting.

To that end, we have divided the paper into dialogue between two educators; one from the era of chalk and blackboards, and the other from the cutting edge of educational technology. The first will present the obstacle, the second the solution, and finally a joint reflection of the degree of success.

\section{Historical Background}

Higher education has come a long way from the image of Socrates sitting under an olive tree dispensing philosophical thought and encouraging critical thinking to eager (wealthy, male) students. It was not until the $12^{\text {th }}$ Century the formalized university structure, which until recently, was the only acceptable way to achieve a college education. Less than fifty years ago the higher educational structure took a dynamic leap forward in its evolution, moving away from the traditional "brick and mortar" university.

In 1971, Dr. David Chigos founded National University (NU) as a non-profit university, fully accredited by the WASC Senior College and University Commission. Chigos recognized the traditional model of higher education did not serve a large population of adult learners. Focused on the older working adult learner, the average student at NU is 33 years old. Courses at NU are one month in length, and students take one course at a time.

Another practical approach at National University is the use of academics who have worked in the particular discipline in which they teach. This is true for adjuncts and full-time faculty. While bringing a wealth of practical knowledge to the classroom, many of the full-time faculty at National University are in their second career; nursing, law enforcement, engineering, teaching, and law. The obvious, is that like their older students, so too are the faculty, older.

National University was one of the first universities to implement online distance education; delivery of lectures and assignments in a virtual classroom setting. By 2005, approximately $15 \%$ of all classes at National University were taught in an online delivery format, and $85 \%$ in a more traditional on-site format. By 2019, the numbers have flipped.

Now, approximately $85 \%$ of courses at NU are offered online, including hybrid courses (part online/part onsite), asynchronous delivery, and adaptive learning. As an older instructor, these course formats seem to move at an exponential rate and in a multitude of directions. Many feel as though it is hard to keep up, and with that feeling, a disconnect with their students. But we are all lifetime learners and falling behind is really not an option.

\section{Online Teaching Professional Development Program}

As a response to the rapid changes in online delivery, NU's Center for Innovation in Learning ("CIL"), created an online teaching professional development program for faculty to learn new tools and strategies to engage students in the online classroom. Professor Hamlin participated in the professional development program and Dr. Leslie (Heather) designed and facilitated the program, which is how she met Dr. Hamlin (Jack). A few months later, Jack invited Heather to team-teach an online course with him titled Facilitation Fundamentals (Appendix A). They re-designed the course and used new approaches to engage students. 


\section{Challenges and Resolutions \\ Age}

(Jack): Long ago, I gave up using age as an indicator for anything academic. We all come to the table with a wealth of knowledge and it is a matter of opening our minds to learn from each other. I often learn just as much from my students as they do me. My exposure to bell hooks' Teaching to Transgress, was a serendipitous and fortunate connection in my early academic career. That said, I do not view my relationship with technological advances with the same synergistic eye. In in a world with technological advances moving at an exponential rate, those changes can be down-right daunting to older folk.

As a background, my technological advances as an undergraduate were moving from a slide rule to a Texas instrument calculator. My early research was collated on punch cards and a simple correlation study could take days for results. I spent days combing the stacks to find just the right article to support my hypothesis. The words "Fortran" and "Cobol" still send shivers down my spine as I recall one ill-fated programing class in my undergraduate studies.

It is not that I am afraid of change. Admittedly, however, I approach technological change with more than a little temerity (I have been known to delete entire files because I was not clear on whether I should "save" or "cancel" and I live in constant fear of launching missiles from their silos in Kansas).

(Heather): I have been working in online course design for the past 8 years and have experience using technology for online teaching. I find technology to be pretty intuitive to use and spend a good chunk of my time in front of a screen or interacting in a virtual space. I just finished a Masters degree in Adult Education that is $100 \%$ asynchronous online.

Professor Hamlin and I did not get along when we first met. I met Jack and through an online teaching professional development program I was facilitating, and we had exchanged a few emails back and forth and were not seeing eye to eye. After things had escalated to the point where the dean was copied on an email, I decided I better go talk to him in-person. Turns out, Jack was simply frustrated with using the technology in the online course. You see, we each have a different perspective when it comes to technology.

For the last few years I have been working in online course design and have experience using technology for online teaching. Jack has also seen lots of technological changes and fads during his teaching career, which centers for academic technology have initiated faculty to adopt. For him technology hasn't always been intuitive and the benefits on student learning have not always been clear. Even though we each bring a different perspective, it turns out we also have a complimentary skillset when it comes to teaching online.

Jack is a polished public speaker and has expertise in explaining concepts in ways that students understand. Jack is also a master storyteller and has a gift using personal anecdotes and stories to engage students. He has been very successful in using his style of teaching to engage students in onsite classes but has sometimes found it difficult to translate his teaching to the online modality. I asked if we could work through some of the issues he was having in teaching his online course. We went through his course and he explained some of the activities he was having trouble implementing online such as a negotiation simulation, which has worked really well for onsite classes. We worked together to translate these activities into the online class using technology tools available in the Learning Management System (LMS).

\section{Communication}

(Jack): My past professions (law enforcement, trial lawyer, pro tem judge, mediator) relied heavily on face to face contact. The need to hear vocal inflections, "read" another's face and body, and physical setting were and remain, important tools in the communication process. In an online setting, those are lost. We end up relying on the words typed out in a hurried email or spontaneous text, losing much of the subtly of a face to face in encounter.

This is a true obstacle to teaching in an online format. It became crystal clear when I took the online teaching professional development program as a learner. No matter how many job aids were provided, and emails exchanged, I found myself further and further behind. This added to my frustration and my 
desire to complete the course. Finally, the email exchanges between my teacher and me became a little too heated (particularly from my end).

(Heather): I had my own assumptions and didn't realize how frustrated Prof Hamlin was with the technology. Once I met with him face-to-face, I better understood what he was dealing with, and I think that this was an important lesson of how easy it is for misunderstandings to occur over email or in written correspondence. Luckily, we were able to resolve the issue and ultimately this is what led us to teamteach a course together.

\section{Where Is Everything? How Do I make This Work?}

(Jack): The original LMS to which I was exposed and taught was Blackboard. About the time I figured that system out, NU switched to eCollege. After limping through that LMS for several years, NU returned to Blackboard, with a whole new bunch of "bells and whistles," including Collaborate Ultra.

Even teaching several courses annually in the Blackboard LMS, keeping copious notes of where to find and use the different tools available, I found myself relying on just the basics. And the basics were giving a lecture online, responding to emails, and grading assignments put into drop boxes (often with limited feedback). In other words, I was teaching similarly to what I would do in an onsite classroom with less student interaction. I simply did not understand how to use the tools, nor did I have sufficient exposure to those tools to use them effectively. I knew that I could provide a richer and more robust learning experience, but I became stymied at my lack of ability.

(Heather): One of the biggest challenges of teaching online is replicating that same feeling of togetherness that one feels in an in-person classroom to an online class. This feeling comes very naturally in an on-ground class because students and professor are physically together. This becomes more difficult when you are distanced by time and space.

\section{Can't See Their Faces}

(Jack): Perhaps the aspect I miss the most when teaching online is seeing the faces of my students. I believe there is no educator who will argue with me just how particularly fulfilling it is, when discussing a complex topic in the classroom setting, and the "Ah Ha" moment occurs. The moment in which a student or students grasp a subject with understanding when moments before it was simply an abstraction.

Despite University requirements to the contrary, most online students do not have functional microphones and cameras. Not only am I unable to see their faces, but when I pose a question, the entire class is halted while a barely coherent text is typed out to respond in the chatroom's textbox. It certainly slows the class, but also limits the manner in which I was able to engage the students. (Socratic method in a text chat? I think not). In turn, the students feel marginalized and the instructor, frustrated and, at worst, disengaged.

(Heather): I agree that if students are going to attend a live synchronous session, they have to do more than text in a chat box. It is because we can't see their faces that student participation (using a microphone or phone to call in) is so essential. It's important to set ground rules for student participation in the beginning of the course so they know what is expected of them and how they should participate in class.

\section{Group Activities}

(Jack): In an on-site classroom setting, I used break-out sessions creating small groups to discuss a variety of topics or engage in an exercise. The particular benefit was exposing students to different perspectives in a synchronous setting. While the exterior goal was to provide the students with an opportunity to exchange ideas and work as a team, the internal goal was to teach students how to engage in civil discourse while working through complex and controversial subjects. In an online setting, I learned to use simple break-out groups, but I had difficulty monitoring the group and then subsequently integrating the various artefacts from each group. Further, as an Alternative Dispute Resolution instructor, I found it difficult to create mock mediation and negotiation exercises. 
(Heather): We worked together to re-create the negotiation exercise in Professor Hamlin's online course using tools available in the LMS. As a pretty advanced Blackboard user, I even hit a few road blocks where I had to call the Blackboard Support, but I was able to figure it out with some help.

\section{Team Approach}

(Jack): Now it was time to put all these new tools to use. In August 2018, I was scheduled to teach a course in Facilitation. Admittedly, I was fortunate to be paired with Dr. Leslie as an instructor. She agreed to team teach with me. But to believe that this was in anyway unusual, would be a mistake.

When I was a rookie police officer, just out of the academy, I was not given a badge, a gun and cruiser and told to go forth and arrest. No, I was teamed with senior officers (Field Training Officers or FTOs) for several months who focused on exposing me to routine and extraordinary situations in the field. When I first passed the bar in California, I was not thrown into the courtroom and told sink or swim. No, I worked with more experienced counsel who taught me the "ropes" of courtroom procedure and etiquette. Even the faculty at NU go through and orientation and teaching evaluations. But not so, with a new LMS.

\section{Redesigning the Facilitation Course to Engage Adult Learners}

Together, we went through the Facilitation course and made some enhancements. Adult learners are engaged by learning practical skills that they can immediately apply (Merriam \& Bierema, 2014). We decided to replace some traditional assessments such as papers and exams with authentic activities so that students could gain some real-world skills in facilitation. We had students facilitate a threaded discussion and facilitate a live webinar with their peers to give them practice using facilitation skills. As instructors teaching the course, it was important for us to model good facilitation practices both in discussion board activities and in live, synchronous sessions. We decided to replace the weekly lecture sessions with interactive learning sessions where students were required to be active participators rather than passive listeners.

We set ground rules during the first live session and showed students how to use various tools in the Collaborate session to participate such as raising their hand, using the chat, microphone, and white board. This set the tone and expectations for students. Adult learners have a lot of knowledge and experience to share. Asking adult learners to participate and share their knowledge and experience as it relates to the course, is an effective strategy for engaging adults. These sessions were very interactive and student surveys indicate that students found these sessions to be engaging and effective for their learning.

In terms of how we would assess students for their final project (the webinar), we had students come up with the criteria for evaluation together as a class activity. This modeled to students the process of coming to a group consensus and group decision making, important aspects of facilitation. This also created more accountability, responsibility, and buy-in for students since they were the ones coming up with the criteria for how they would be evaluated. Adult learners want to have input on how they are evaluated so this strategy followed that principle (Merriam \& Bierema, 2014). We also crafted a discussion board scenario where students had to plan to facilitate a community forum after a police shooting of an unarmed black man. This scenario appeals to adult learners' desire to solve problems that are authentic and real-world based (Merriam \& Bierema, 2014). We also added interactive videos to the course to add variety to the format of course content so it was not just textbook reading and Power Point presentations in order to engage different types of learners. For the facilitation activity in which students had to facilitate a threaded discussion, we provided an instructional video that explained the rubric as well as examples of "good" discussion board posts and "bad" discussion board posts.

In order to create that feeling of togetherness, we used a lot of videos to humanize ourselves in the course when sending announcements, instructions, presentations, or answering student questions one-onone. This added our instructor presence to the course where students had a closer connection to their instructors in an online environment. The technology tool we used to create videos was Kaltura video software. Knowing how to use these tools helped us to humanize the course for students so they could know us better and be more engaged. 
Even though technology helped us to humanize ourselves, technology was not the focus. We focused on student engagement, adult learning, and facilitation practices as the primary objectives for the redesign of this course. Technology was simply a way to leverage our objectives rather than an objective in and of itself. We both agreed that we would not use technology for technology's sake. Rather, the objectives and the pedagogy had to drive the use of technology, not the other way around. Once we were clear on what we wanted to accomplish, we could inventory our tools to find the ones to accomplish the objective. For example, we knew we wanted students to be able to facilitate as part of this course. The tools we used to achieve those objectives were the discussion board tool and the synchronous web conferencing tool (Blackboard Collaborate Ultra) as the mediums for students to facilitate. We also showed students how to use the tools to engage their peers. We surveyed students during and after the course to get their input on the new re-design. After surveying students, many reported that they felt they were engaged in the course. One student said, "I really like all the different ways we have to engage in this class, like Blackboard Ultra, polling, discussion boards, etc. I feel like we are taking advantage of all the technology we have."

\section{Key Success Factors}

(Jack): The team approach allowed me the freedom teach in the manner in which I worked for years, and at the same time experimenting with a safety net. Additionally, the approach allowed me to become an occasional observer of student engagement and adaptability to a robust use of technology. While still virtual, there was much more an assemblance of the traditional classroom setting. The blending of "old school" and "new school" produced high student satisfaction with the course subject matter and the instructors.

(Heather): Using a team-teaching approach allowed us to learn a lot from each other. I learned a great deal from Professor Hamlin particularly in his mastery of using the didactic method to expertly explain course concepts and engage students through powerful means such as storytelling and authentic scenarios. What I think I brought to the table is an approach aimed at maximizing student engagement through active learning and participation. Each of us brought a different style but, collectively, our goal was to engage students, and to that end, we were successful.

\section{CONCLUSION AND REFLECTIONS}

Being able to engage learners is a necessary skill for educators. The mark of a good teacher is to turn attendance, which can be required, into learning, which cannot. And in order for students to learn, they need to be engaged and participating. As the instructor, the only way we can assess student learning is by having students participate. In order to get students to participate, the instructor has to create an environment where students feel comfortable to participate. Students need to understand that their participation is essential to their learning. Students need to be prepared to participate in all aspects of the course, whether it's in a discussion board or in a synchronous meeting, or in a physical classroom. This may be difficult for some students who are nervous to put themselves out there in front of their peers, for fear of appearing unintelligent or unprepared. This is why the job of facilitator is so important. A facilitator is able to bring people into the conversation like a skilled conductor of an orchestra. Students' contributions to the class, together with their peers, create a musical symphony where they each play an instrumental role in the overall learning community. In order to get students to participate, they need to feel like their voice, thoughts, perspective, and input matters.

Expectations for participation need to be communicated as ground rules for engagement that all students agree to and take part in shaping at the beginning of the course in order to create ownership and accountability. At the same time, the goal for the teacher should be to create an environment of trust where all contributions are valued and consensus is built around the classroom being a judgement-free zone when it comes to making mistakes or being wrong because when that happens, we all learn. Students have to unlearn their conceptions when it comes to failure. Many people fear failure but F.A.I.L. stands for First Attempt In Learning. 
When we feel comfortable to fail without shame or embarrassment, we can authentically learn. As instructors, we also have to be willing to be vulnerable and demonstrate to students that we fail all the time too because that's what learning is. Professor Hamlin and I tried to create an environment where students felt comfortable to fail in front of their peers. We did this by modeling good facilitation practice, acknowledging every student's contribution to the class discussions, showing interest in what students have to say, and creating teachable moments when students had confusion or misunderstanding. It's just as important, if not more important, to express gratitude to students who say the wrong answer as those who say the right answer, because this helps teachers focus on where students need instruction or clarification. If students are afraid to speak up, out of fear of being wrong, a teaching opportunity is missed. We reinforced the building of a trusting and supportive classroom climate by asking students to help their classmates feel comfortable to participate. This is an important job of a facilitator, and this class was about teaching students how to facilitate.

We invited students to participate especially when they didn't understand something because this is where teaching needs to happen and where learning happens. We would use a technique where if one student spoke up and said a wrong answer, we would thank that student and say this is a common misunderstanding and ask other students to chime in if they also had confusion. This would assure the student who went out on a limb that they were not alone and that others felt the same way. It's important to understand that teachers need to pay extra attention to creating an inviting and inclusive classroom climate in online classes, because the nature of being separated by time and space makes it easy to feel isolated. Studies have shown that students want personal attention from their professors and that robust communication has a positive impact on student outcomes.

Team-teaching this course was a great learning experience for both of us because we each got to contribute our strengths to the course and learn from each other's teaching approach, which resulted in a better learning experience for students. I come from a constructivist teaching philosophy in that I think students learn best by reflecting on their experience and co-creating knowledge together, collaboratively. Many universities, including NU, have an institutional learning outcome for their students to be able to use collaboration and group processes to achieve a common goal. We live in an interconnected and interdependent world and being able to collaborate to solve problems is becoming an increasingly important skill in any occupation. Why should teaching be any different? Why is teaching done with oneteacher-to-many-students and is this the most efficient and effective way to improve teaching effectiveness and student outcomes, particularly with an increased focus on student retention and graduation? With new models being developed such as personalized learning and competency-based education, can the job of teaching be redefined as a collaborative activity? Teaching has traditionally been an isolated activity, where teachers and departments work in silos without much collaboration. This can stifle innovation and ability to adapt to fast paced changes. In the future, universities will need to have organizational designs that have flexible structures based on teams to be innovative and adjust to the needs of students and employers. The journey to innovation occurs through collaboration. A team-based approach to teaching can not only produce better learning outcomes and support for students but also can have the same effect on faculty teaching the course, at least that has been our experience.

\section{REFERENCES}

Hooks, B. (1994) Teaching to Transgress. Philadelphia, PA: Routledge Press.

Merriam, S., \& Bierema, L. (2014). Adult learning: Linking theory and practice. San Francisco, CA: Jossey-Bass. 